\title{
Pri-Sci-Net - A Project Promoting Inquiry-based Learning in Primary Science: Experiences of Young Children Inquiring
}

\author{
${ }^{1}$ Suzanne Gatt, ${ }^{2}$ LauraSue Armeni \\ ${ }^{1}$ University of Malta, Malta \\ ${ }^{2}$ Malta Council for Science and Technology, Malta
}

\begin{abstract}
One of the challenges of Science Education in the $21^{\text {st }}$ century is that of engaging learners in meaningful learning. Learning science from books does not equip them with the skills and competences necessary to become scientists. The European Commission [1] has recognized this challenge and advocated inquiry-based learning as the main pedagogy to be adopted for teaching science. This paper presents the work in progress of the FP7 project Pri-Sci-Net which aims to promote inquirybased learning approaches at primary level of education with children from age 3-11 years across Europe. There needs to be a shared understanding among teachers of inquiry with reference to young children, and consequently identifying the required pedagogical skills. In addition, teachers need resources which they can gain through sharing their experiences with other teachers. The paper puts forward a vision for inquiry-based learning, highlights the need for the training teachers, and explores the potential of a virtual platform which can promote CPD for the use of IBSE among teachers.
\end{abstract}

\section{Introduction}

The main challenge for Science Education in the 21st century is that of engaging students in the learning process in a meaningful way. Learning science with the teacher as simply the transmitter of knowledge with students as passive recipients bores students and puts them off from doing science. Students would then be less likely to choose science as a career. This transmission approach [2] used to promote learning also does not equip students with the skills and competences necessary for becoming scientists. Scientists need to be able to question, design investigations, and to work with the limited evidence which their results provide in order to understand better how the world works as well as to develop ways of providing a better quality of life, whether in terms of health, engineering, environment or agriculture. Inquiry skills are also necessary for students who do not intend to become scientists. This is because as active citizens, they need to understand scientific issues, form opinions related to social aspects of scientific enterprise as well as express these opinions in different fora as part of participatory governance. The challenges of science education to cater for preparing future scientists as well as educate for science citizenship are great and the solution is surely not an easy one.

Historically, the aim of science education has focused mainly on the first aim - that of producing future scientists, and less on the educating students for scientific literacy and citizenship [3]. This legacy has led to the development of current science curricula which are loaded with scientific knowledge and limited time for experimentation and reflection. This resulting curriculum often deprives students from understanding the process and nature of science. This state of science education has been acknowledged by main science educators [3] and there is agreement that there needs to be a change in the quality and type of science education that is offered in schools. There should be more space for students to explore the nature of science and how scientists work to understand better how nature works and to develop new technologies [3]. This cannot be achieved through the transmission approach to learning science.

The Science Education Standards established by the American Association for the Advancement of Science (AAAS) and the US National Research Council (NRC) have long provided evidence to support a change in emphasis for learning from the simple memorization of scientific facts to the process of learning through investigation of the everyday world by Inquiry-Based Sience Education (IBSE) approaches. Their findings indicate that students who are low achievers in science have a higher successful rate when inquiry-based learning is coupled with careful syllabus development and professional development for its drivers, the teachers [4]. This applies for students both at primary and secondary level. Moreover IBSE is also beneficial in promoting science with girls as they enjoy participating in science activities and can pursue aspects of science which are more to their interest. Inquiry-based learning thus works in favour of promoting better attitudes towards science, particularly among girls who tend to be less enthusiastic.

In addition, research shows that through inquiry-based learning, children tend to reflect more 
on their own everyday direct experiences of the world around them when using scientific knowledge [5][6]. Students rarely use or fall back on knowledge that they have gained in traditional ways, often detached from reality. This highlights the great need, especially for young children to experience and live science rather than reading about it. It is thus of great importance to help primary teachers to develop the skills in using Inquiry based learning and approaches which promote the engagement of children in science. Fortunately gender differences in science would have not appeared at primary [7]. This does not mean that the gender dimension does not need to be taken into consideration as gender differences appear if no positive experiences are provided. This would otherwise result instead with boys holding more positive attitudes [8] and thus missing out on the potential which girls have to contribute to science.

At primary level, inquiry based learning is perfectly adapted to young children and appropriate for introducing science education. Inquiry makes the best use of the children's innate tendency to want to ask questions and curiosity to learn and know more about the world around them. Inquiry is a way of feeding students' appetite when they are still in their 'curiosity golden age' [9]. Having said this, it is to be acknowledged that there are already many dynamic teachers who have developed multiple innovative practices. They have developed ideas and approaches which fit within the inquiry approach and consequently they are an untapped resource.

The European Commission [1] has recognised the shortcoming of current pedagogical practices at both primary and secondary level of education and advocates the implementation of inquiry-based learning as the main pedagogical approach for teaching science across the EU Member States. Inquiry provides students both with skills which provide the basis for scientific literacy as well as equips those who want to become scientists with the process and cognitive skills needed for becoming drivers of research and innovation. Inquiry-based learning in science also promotes better attitudes among students for the subject as it engages students more than the traditional approach. A study by Gibson and Chase found that students who were taught using the inquiry-based approach maintained a more positive attitude towards science and a higher interest in science careers than the control group of students who were not selected for the programme [10].

In recognizing the necessary shift in teaching pedagogy in science education, it is acknowledged that the efficacy of reform efforts is largely attributed to how much educators are ready to take on the challenge and to change their approach to science education at both primary and secondary level of education [11]. The European Commission has been through its framework programme investing in transnational projects which work to develop science activities using IBSE and to train teachers across Europe. One of these projects is PRI-SCI-NET, which similar to other projects is ensuring that the educators' voice is included in the design and implementation of inquiry-based learning. It is ensuring that the accumulated knowledge, experiences and observations developed in parts of Europe are shared between peers across Europe through open communication platforms, national and international trainings and conferences.

This paper presents the work in progress of the FP7 project Pri-Sci-Net which works to promote the uptake of inquiry-based learning approaches at primary level with children from age 3-11 years at a European level.

\section{Background to the project and its activities}

PRI-SCI-NET is an EU funded FP7 Supporting and coordinating action (Call SiS-2010-2.2.1.1) on innovative methods in science education: teacher training on inquiry based teaching methods on a large scale in Europe. The project is coordinated by the Malta Council for Science and Technology (MCST) and has 17 partners from 14 countries. The project started in September 2011 and is three years long.

The project promotes the use of the Inquiry-based learning approach among primary teachers teaching science to young children in the age range of 3-11 years. In doing so it has brought together a group of science educators from all over Europe specialising in primary science education to develop together 45 inquiry-based activities for children between the ages of 3 and 11 years [12]. The project also intends to set up a Europe-wide network for professionals and academics in the area of Primary Science Education. Furthermore, as PRI-SCI-NET acknowledges the need to train and network primary teachers, teachertrainers and educators as part of their professional development there is a significant investment in national and international teacher-training and conferences across Europe. The training and professional support to teachers aims to help them use Inquiry based learning in Science in schools. A virtual platform at European level will also be developed to network professionals as well as support the organisation of training courses. The project also recognizes teachers' and researchers' achievements through a Certificate of Excellence.

The project will concurrently also take small projects in primary science education, and promote them on a larger scale in order to provide examples of Inquiry Based teaching approaches to have an impact at European level. The project is built on several previous projects, mainly: using an already 
developed theoretical pedagogical model for the teaching of science at primary level for developing teaching resources (developed as part of Comenius 1 and 2 projects); utilising the European network for primary school teachers to provide training and professional development to primary science teacher trainers; as well as providing in-service training opportunities based on experience of partners in implementing ERASMUS intensive courses for primary school teachers on a national and international level. PRI-SCI-NET aims to establish a European community of primary science educators working within the Inquiry Based approach [12].

\section{The Vision for Inquiry-based learning in Science}

Inquiry-based Science education has for long been advocated in the U.S. In December 1995 the National Research Council (NRC) released the National Science Education Standards based on a vision of science education that would make scientific literacy for all a reality in the $21 \mathrm{st}$ century. A prominent feature of the Standards was a focus on inquiry. The term "inquiry" was used in two different ways in the Standards. First, referring to the abilities students should develop to be able to design and conduct scientific investigations and to the understandings they should gain about the nature of scientific inquiry. Second, it referred also to the teaching and learning strategies that enable scientific concepts to be mastered through investigations. In this way, the Standards drew connections between learning science, learning to do science, and learning about science. A practical guide for teachers, professional developers, administrators, and others who wished to respond to the Standards' call for an increased emphasis on inquiry was developed [13].

The Pri-Sci-Net team of about 30 primary science educators from a number of EU Member States have worked together to develop the vision for inquirybased learning in science which they want to promote when doing science with young children. The team believe that a strong vision is needed, not only so that all the different partners share the same understanding of the type of inquiry which they would like to promote across Europe, but also because a clear vision would make the message put forward stronger. Current thinking in education circles on the nature and techniques used in inquirybased learning were considered, and together with their personal experience and views, the partners have developed a vision which is reflected in all the project's activities.

This the Vision for doing inquiry with young children within the project Pri-Sci-Net: Inquirybased science at primary level is a teaching and learning framework with implications about learning science, learning to do science, and learning about science. In this framework: children

- engage actively in the learning process with emphasis on observations and experiences as sources of evidence;

- tackle authentic and problem based learning activities where the correctness of an answer is evaluated only with respect to the available evidence and getting to a correct answer may not be the main priority;

- practice and develop the skills of systematic observation, questioning, planning and recording to obtain evidence;

- participate in collaborative group work, interact in a social context, construct discursive argumentation and communicate with others as the main process of learning;

- develop autonomy and self-regulation through experience;

The teacher scaffolds and guides learning by providing a role model of an inquiring learner. The teacher does not function, in the eyes of the children, as the sole bearer of expert knowledge. Instead, the main role of the teacher is to facilitate negotiation of ideas and to highlight criteria for formulating classroom knowledge. This builds on Constructivist view of learning that provides theoretical support for teachers to have a role as facilitators in the students' process of reconstructing their knowledge by interacting with objects in the environment and engaging in higher-level thinking and inquiry based problem solving [14]. The assessment framework within such a vision is mainly formative, providing feedback to the teaching and learning process for all classroom participants. Written examinations leave little space for inquiry and promote too much rote learning. Thus formative assessment is considered to be more appropriate.

\section{Activities started so far}

Pri-Sci-Net is about promoting Inquiry-based learning in science at primary level of education through developing activities for teachers to use as well as setting up a Europe-wide network for professionals and academics in the area of Primary Science Education. This is based on the premise that inquiry based experiences provide priceless opportunities for students to progress their understanding both with respect to scientific content as well as in how to inquire and science process practices involved when carrying out investigations. Inquiry also supports the further development of positive attitudes towards scientific careers [15].

The project aims to achieve this vision through a number of actions aimed primarily at teachers and teacher educators and researchers. The envisaged actions include: 
- Development of 45 science teaching activities using IBSE in 15 different languages. These activities have already been professionally developed and trialed in one country;

- Recognition of Excellence for teachers implementing IBSE at primary. Teachers can apply for this Certificate and share their good practice with other teachers;

- Two International conferences in Cyprus and in Malta. The first conference will be held as part of the ESERA conference in Cyprus 2013;

- Four 20-hour national training on IBSE for teachers and teacher-trainers in each of the 13 partner countries. All the partner countries will provide training to primary school teachers;

- Three international teacher-training courses. There will also be opportunities to support the participation to training courses across all Europe;

- A virtual European network platform for teachers and researchers in primary science. This virtual platform will be able to tackle different languages as well as allow teachers to share their knowledge and experience;

- An online newsletter and a research journal on IBSE in primary science. The team also wishes to place teaching of primary science on an academic standing as other areas in science education;

\section{Preliminary Findings}

Project activities completed to date include the design, formulation and translation of 45 primary science activities in different languages which are currently being trialled for linguistic and cultural adaptation in schools across Europe. The partners are currently trialling out samples of the activities in classrooms, where teachers are delivering the activities and, together with the researchers, are seeing how they can be adapted for language translation.

In Malta, some trials have already been carried out by a number of pre-school and primary teachers as part of their professional training. These preliminary results show a renewed enthusiasm in teachers as they become aware on the degree to which young children of as little as 3 years old can inquire in science. There are many accounts of how children could concentrate and carry out systematic observations over a period of time. Young children could also reflect and arrive to simple conclusions the observations made. The actions and content may be simple, but the seeds of inquiry can be sowed already at such a young age. If such inquiry approach can be developed and sustained throughout primary education, then the upcoming generations would have acquired the cognitive ability to deal with problems and how to find solutions from the information and evidence available.

The preliminary results also show how important it is that the activities promoted by the project to allow space for teachers to adapt them to their context. Many times teachers already have their own resources and it is both expensive and time demanding to buy new resources in order to deliver lessons exactly as they have been designed by somebody else. The activities were found to be flexible to ensure that teachers can use their own available resources by simply adapting the context of the science activity. The teachers have managed to adapt the story-telling perspective while keeping the investigation's characteristics close to the original version. Many teachers observed a high level of interaction among young children between the ages of 3-5 years old. Many of the teachers were also surprised to notice the level of insight and evaluation of evidence which the children better successful implementation was noted when the activities implemented were done using the mother tongue of the student, careful classroom management was implemented and activities were tailored for the audience receiving them [16].

Networking is one main tool for promoting professional development and training in the use of Inquiry based learning in science by primary school professionals at different levels of the different education systems across Europe. Teachers in primary schools are mainly confined to their classroom with their daily business of teaching. They have little time during their working day outside their classroom. The time for in-service training thus becomes limited. As a result, teachers can easily end up isolated and limited to the confines of their classroom and their school. They have very few opportunities to share their professional lives with other professionals in education. This creates a barrier to their professional growth which can have serious repercussions on their impact in the classroom and the education system overall [17]. Networking among teachers needs to be promoted and recommended in the Rocard Report [1]. Teachers are key in the renewal of science education, and being part of a network provides opportunities to improve the quality of teaching and supports motivation. Networks promote cooperation within and between schools, collaborative reflection, development and evaluation of instruction, exchange of ideas, materials and experiences, quality development, cooperation between teachers and researchers and support and stimulation from research. Hence, networks can be an effective component of teachers' professional development and complement the more traditional forms of teacher in-service training [1]. Another deliverable within the project targets this specifically this aspect of networking among teachers. Work is in full swing 
to finalize the development of a virtual platform at European level where professionals can network and share their experiences and successes.

This is also intended to enable the recognition of teachers' and researchers' achievements in implementing Inquiry-based learning in science. Many times teachers work hard and provide a good service within the walls of their classroom, with little recognition beyond that of their pupils and their families. It is important to both teachers and students to recognise good practice and to give value to the good work done. Not only does it motivate the individual teachers involved to continue with their work, but they also serve as role models and champions such that other teachers can follow and adopt these good practices. It is for this reason that Pri-Sci-Net has developed a Certificate of Excellence in IBSE for primary teachers, such that valuable work is given its due credit. This year this Certificate has been extended to recognise also the commitment demonstrated at school level.

The project also intends to provide opportunities for the training of teachers and other educators by providing an opportunity for teachers and academics to attend national and international IBSE training activities [12]. In the initial testing and following field observations and the organization of consultation seminars in Malta, it was found that the concept of the platform was well-received and supports the needs of IBSE users as it moves away from the posting of static material and moves towards the supporting of collaborations, sharing of ideas, networking and building on the works of others in an interactive and easy manner. Challenges in setting up such platform exist. One major challenge is that of ensuring excellence in the quality of the activities and discussions in which teachers are involved. The project team are committed to invest in making the required efforts to achieve and maintain the platform alive until there are enough teachers who are members and who will keep the platform going beyond the lifetime of the project.

\section{Conclusion}

The initial results of the project show how well the activities were chosen. It is to be noted that so far activities that were developed in diverse European countries e.g. Belgium, Cyprus, France, Slovakia, Austria and other countries could easily be adapted to other contexts. This goes to show how good pedagogical approaches have the potential of transferability from one country to another if translations are made taking into consideration linguistic and cultural differences. The enthusiasm expressed by the teachers also provides insight into how to bring about change in pedagogic practices. Teachers need materials which they can adapt and develop to reflect their classroom needs and do not make significant resource demand. It is thus very important to avoid being prescriptive but to allow space for flexibility. One of the main strengths of the activities is that they tend to provide inspiration and guidance rather than are prescriptive. The bigger challenge is that of encouraging teachers to share their own activities with other teachers. Many times teachers like to look up for resources and to download them. They are less eager, however, to share their own ideas and initiatives. This may be either due to teachers being used to working alone within the four walls of their classroom, or else reflect a need to develop a better sense of sharing as part of professional development within the teaching profession.

The project aims to keep on encouraging teachers and to follow further how more teachers in other countries can take up inquiry as advocated by PriSci-Net in order to invest in a better future generation of citizens as well as of scientists. The road is a long and hard one, but if inquiry starts to spread, it can at one point, possibly, really become the main pedagogy in the primary science classroom.

\section{References}

[1] European Commission, (2000), Lisbon Strategy, Council of European Ministers.

[2] Sutton C. (1992). Words, Science and Learning, Milton Keynes. Open University Press

[3] Osborne J., Dillon, J., (2008). Science Education in Europe: Critical Reflections: A report to the Nuffield Foundation, United Kingdom: King's College London.

[4] Marx, R. W., Blumenfeld, P. C., Krajcik, J. S., Fishman, B., Soloway, E., Geier, R. and Tal, R. T. (2004). Inquiry-based science in the middle grades: Assessment of learning in urban systemic reform. J. Journal of Research in Science Teaching, 41: 10631080.

[5]Gatt, S. (2008). The impact of the Bologna Process on Higher Education Institutions in Malta: An overview of the achieved targets and future challenges, Research paper prepared for the Bologna Experts Group, Malta.

[6] Gatt, S. \& Gatt, K. (2007). Skills developed in the Fair Trade Sector: Malta Case Study, Journal of Mental Changes, Volume XIII, 2007, 1-2, 315-336

[7] Haworth C, Dale P, Plomin R. , (2008),A twin study into the genetic and environmental influences on academic performance in science in nine-year-old boys and girls. International Journal of Science Education 30(8):1003-25. 
[8] Weinburgh M., (1995), Gender differences in student attitudes toward science: a meta -analysis of the literature from 1970 to 1991 , Journal of Research in Science Teaching 1995;32(4):387-98.

[9] Rocard, M., Csermely P., Jorde D., Lenzen D., Walberg -Henriksson, H., Hemme V., (2007), Science Education now: A renewed Pedagogy for the Future of Europe, Brussels: European Commission.

[10] Gibson, H. L. and Chase, C. (2002). Longitudinal impact of an inquiry-based science program on middle school students' attitudes toward science. Science Education, 86: 693-705.

[11] Keys, C. W. and Bryan, L. A. (2001), Coconstructing inquiry-based science with teachers: Essential research for lasting reform. Journal of Research in Science Teaching, 38: 631-645.

[12] PRI-SCI-NET Project Website. (2012). Taken from: http://www.prisci.net/ on $12^{\text {th }}$ November 2012.

[13] National Research Council, (2000), Inquiry and the National Science Education Standards: A Guide for Teaching and Learning, National Academy Press, Washington, D.C.

[14] Crawford, B. A. (2000) Embracing the Essence of Inquiry: New Roles for Science Teachers. Journal of Research in Science Teaching, 37, 9, 916 -937.

[15] Edelson, D.C., Gordin D. N., and Pea R. D. (1999). Addressing the Challenges of Inquiry-Based Learning Through Technology and Curriculum Design. Journal of the Learning Sciences, 8, 3-4.

[16] Carless, D. (2004), Issues in Teachers' Reinterpretation of a Task-Based Innovation in Primary Schools. TESOL Quarterly, 38: 639-662.

[17] Gatt S. \& Costa M., (2009), Networking School Teachers to Promote Better Practice in the Teaching of Science across Europe, European Journal of Education Research, Development and Policy, Volume 44 Issue 4 (December 2009), p 493 -506.

\section{About the project}

The project Pri-Sci-Net has received funding from the European Union Seventh Framework Programme (FP7 2007 /13) under grant agreement No.266647. Any opinion expressed is solely of the authors and does not reflect that held by the European Commission. Project website: www.prisci.net.

The website for the virtual platform is www.social.prisci.net 